\title{
Using MODIS NDVI products for vegetation state monitoring on the oil production territory in Western Siberia
}

\author{
Anton Kovalev ${ }^{1, a}$ and Olga Tokareva ${ }^{1}$ \\ ${ }^{1}$ National Research Tomsk Polytechnic University, 634050 Tomsk, Russia
}

\begin{abstract}
Article describes the results of using remote sensing data for vegetation state monitoring on the oil field territories in Western Siberia. We used MODIS data product providing the normalized difference vegetation index (NDVI) values. Average NDVI values of each studied area were calculated for the period from 2010 to 2015 with one year interval for June, July and August. Analysis was carried out via an open tool of geographic information system QGIS used for spatial analysis and calculation of statistical parameters within chosen polygons. Results are presented in graphs showing the variation of NDVI for each study area and explaining the changes in trend lines for each field. It is shown that the majority of graphs are similar in shape which is caused by similar weather conditions. To confirm these results, we have conducted data analysis including temperature conditions and information about the accidents for each area. Abnormal changes in NDVI values revealed an emergency situation on the Priobskoe oil field caused by the flood in 2015. To sum up, the research results show that vegetation of studied areas is in a sufficiently stable state.
\end{abstract}

\section{Introduction}

Western Siberia is the largest oil and gas basin in 3.5 million kilometers square in space and is one of the main areas for oil and gas production in Russia. Oil and gas industry activity leads to systematic damage to the vegetation as a result of mechanical damage to the surface at the stage of research and infrastructure development of oil and gas producing fields. This damage occurs due to fires, oil spills, oil drilling fluids, and the air pollution impact on vegetation. Therefore, permanent environment monitoring is required on the territories under the constant intensive technological pressure.

The chemical impact of oil and gas industry on environment is caused by toxicity of natural hydrocarbons and chemical substances used in manufacturing processes. Natural recovery processes of the vegetation cover after accidental spills exposure are fairly long so natural components need restoration and reclamation [1]. The problem of accidental oil and various reagents spills is often solved by dumping sand in violation of technological requirements. In these cases the problem is only complicated, because the pollutants remain in the soil and fall into the surface and underground waters.

Gas flares scattered throughout the West Siberian oil and gas province produce very aggressive and dangerous chemical pollution agents [1]. This problem is especially relevant for Khanty-Mansiysk autonomous okrug (KMAO) located in the area of the southern, middle and northern taiga dominated by

${ }^{a}$ Corresponding author : Optimist93@sibmail.com

This is an Open Access article distributed under the terms of the Creative Commons Attribution License 4.0, which permits unrestricted use, distribution, and reproduction in any medium, provided the original work is properly cited. 
coniferous forest particularly sensitive to pollutions [1]. In addition, there are signs of an active pest infestation in the autumn period which is caused by the heating effect of the flares and the subsequent weakened state of the trees.

Nowadays, satellite monitoring data is used in addition to traditional methods of ground-based observations of vegetation cover [2,3]. The remote sensing data allows monitoring of the state and structure of vegetation over large areas, including those hardly accessible for ground survey due to high water logging. In the paper [3] authors discuss the results of using NDVI [2,4], which was calculated with Lansat data (spatial resolution $30 \mathrm{~m}$ ) to evaluate the negative impact of chemical pollution on the state of coniferous trees in the flares' area of influence at Priobskoe oil field. It was shown that the results of remote assessment of the forest vegetation state changes based on vegetation indices sufficiently correspond to these bioindicative ground research results.

The purpose of this study is to evaluate the changes of vegetation in the oil production field territory on the basis of NDVI values using data obtained by the MODIS (Moderate Resolution Imaging Spectroradiometer) instrument [2] with spatial resolution $500 \mathrm{~m}$.

\section{Study areas}

Research was conducted in five oil-producing areas: Khanty-Mansiysk autonomous okrug (UstBalykskoe, Priobskoe, Samotlorskoe and Lyantorskoe oil fields) and in Tomsk region (the Vasuganskaya group of oil fields: Pervomaiskoe, Lomovoe, Olenie, Katylginskoe, Lontynyahskoe). A segment of the Ugansky Park was chosen as a background area. The boundaries of the oil field territories were constructed using Landsat-8 satellite images with a spatial resolution of $30 \mathrm{~m}$, which allows deciphering the field infrastructure (holes, pipelines, roads, etc.). Figure 1 displays a scheme of studied areas shown as polygons of a thematic vector layer on a digital map, where boundaries of the segments are shown in thick black lines.

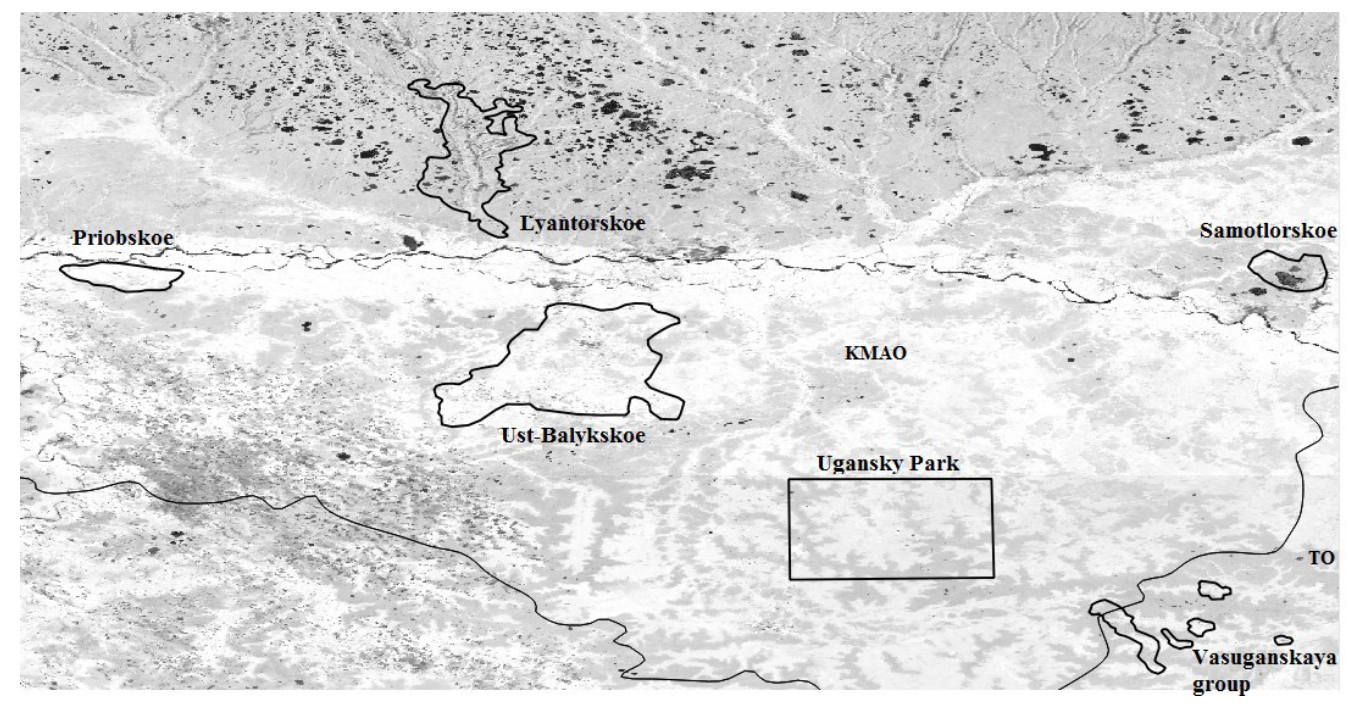

Figure 1. The location scheme of studied areas. Legend: TO - Tomskaya Oblast.

\section{Data and research methods}

NDVI has been chosen for this analysis as it has high sensitivity to biomass changes and is suitable for quantitative measure. It has fixed values for objects not related to vegetation: the value 0.7 corresponds to luxuriant vegetation, 0.5 - sparse vegetation, 0.025 - soil, 0 - clouds, -0.05 - snow and ice, -0.25 - water, -0.5 - man-made materials (e.g. concrete, pavement). According 
to the evaluation of given values from images, a structure of an explored area and vegetation may be considered [4]. Below is the formula of calculation for the index:

$$
\text { NDVI }=\frac{\text { Pnir }- \text { Pred }}{\text { Pnir }+ \text { Pred }}
$$

where Pnir - spectral luminance pixel values in the near infrared range of the electromagnetic spectrum; Pred - in the red range of the spectrum.

Study used MODIS MOD13Q1 Vegetation Indices 16-Day Global 500m with 16-days average NDVI values provided by an online archive of NASA EOSDIS. For the purpose of correct data visualization on the screen NDVI values in provided files are stored with the scale coefficient of 10000. According to the MODIS scheme of a segments location, studied areas are shown on images using numbers $(21,02)$ and $(21,03)$.

Spatial data analysis was selected as the main research method to evaluate characteristics of the region of interest. Spatial analysis was conducted using QGIS tools created to calculate the statistical indicators within the selected polygons.

\section{Results of research}

To study the dynamics of changes in vegetation state within each area, average values of NDVI by year were calculated for the period from 2010 to 2015, with an interval of one year. We used data, obtained from the pictures with recording dates 12.06-27.06, 12.07-27.07. Average NDVI values and trend lines for each study area are shown in Figures 2 and 3. They show that behavior of NDVI changes for each studied area. It is worth noting that NDVI values of the Lyantorskoe and Samotlorskoe oil fields significantly differ from values of other areas (approximately 0.1 less). Such a variation is caused by a lot of swamps within the total area of the field (about $1000 \mathrm{sq} \mathrm{km}$ for Samotlorskoe). As mentioned above, the NDVI value for water is low.

As we can see from Fig. 2, the majority of graphs have similar shapes caused by weather conditions. Analysis of temperature data showed that in 2013 the spring was late and at the beginning of June the weather was cold. It caused delay in building biomass plants at the beginning of vegetation period and explained the reason why NDVI values were low in July 2013 (Fig. 2).

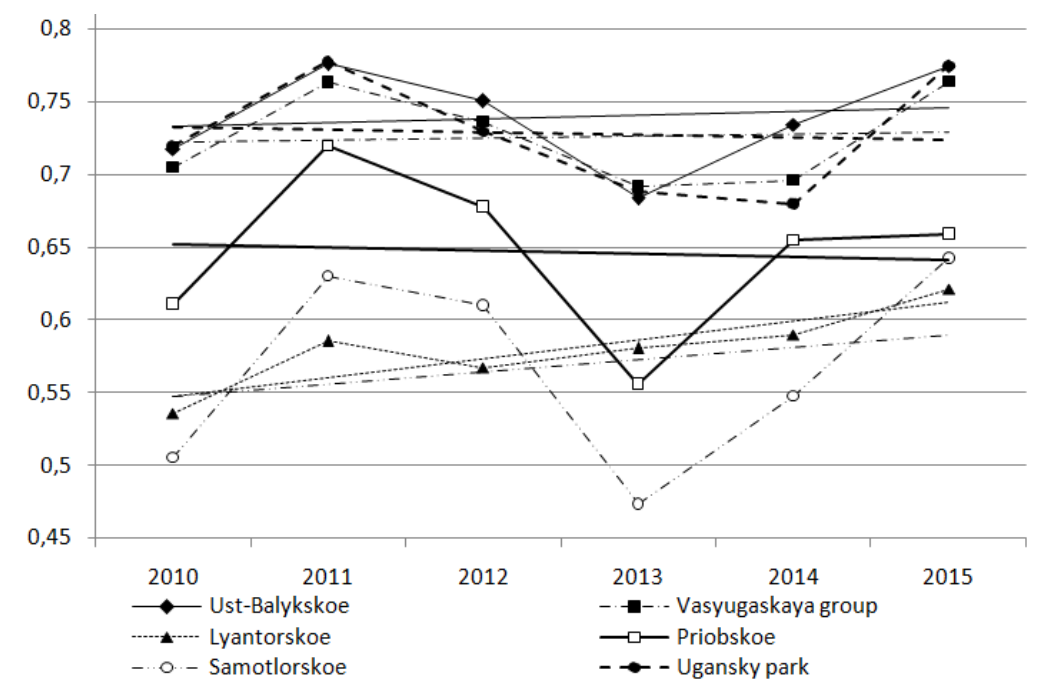

Figure 2. Changes in average NDVI values by year (recording dates 12.06-27.06). 


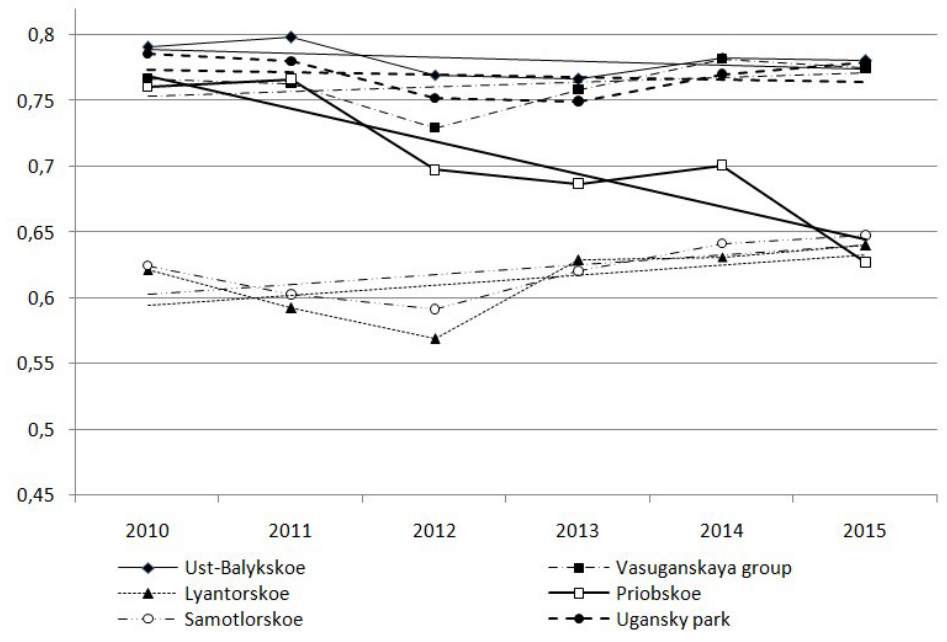

Figure 3. Changes in average NDVI values by year (recording dates 12.07-27.07).

Dry and extremely hot weather in June and July 2012 caused significant reduction of NDVI values in the second half of July in each study area. Slope of the trend lines is not significantly different for the territories of the Ugansky park, Ust-Balykskoe, Priobskoeoil fields and Vasuganskaya group of oil fields. The trend angle of the Lyantorskoe and Samotlorskoe oil fields shows an improvement in the state of vegetation that can be associated with the ongoing remediation work here. At the moment the oil production on the Lyantorskoe oil field is decreased. That causes self-healing processes of land and, therefore, vegetation.

Comparative analysis of trends in Figures 2 and 3 is shown that NDVI values are slightly increasing in July. This fact associated with changes of vegetation period, but in some parts the NDVI values do not change or even decline in July of the same year. For example, in July 2015 there is a significant decrease in NDVI values compared with the values obtained in June on the Priobskoe oil field. NDVI changes on other oil fields are slight. This is explained by a high level of flood waters in July 2015 and a large amount of precipitation. A significant part of territory of the Priobskoe oil field is located in the overflow land of the Ob river. At the end of June 2015 an accident occurred on the oil pipe line on the territory of the Ust-Balykskoe oil field, but the bulk of the oil got into the river.

\section{Conclusion}

We can conclude that vegetation state in the study areas is sufficiently stable. Thermal and water regime has the greatest influence on the average NDVI values here. Comparative analysis of graphs of NDVI values reveals abnormal changes in the territory and determines areas which require a more detailed analysis of the reasons using the ground-truth data and satellite images with high spatial resolution.

\section{References}

1. L. K. Altunina, L. I. Svarovskaya, Y. M. Polishchuk, O. S. Tokareva, Petr. Chem. 51 (5), 381 (2011)

2. T. Hilker, A. I. Lyapustin, F. G. Hall, R. Myneni, Y. Knyazikhin, Y. Yang, Y. Wang, C. J. Tucker, P. J. Sellers, Rem. Sens. of Env. 166, 233 (2015)

3. O. S. Tokareva, Y. M. Polishchuk, Sovr. Prob. Dist. Zond. Zemli iz Kosm. 10 (2), 81 (2013)

4. J. R. Jensen, Remote Sensing of the Environment: At Earth Resource Perspective (Pearson Education, 2011) 